\title{
The Contribution of MMP-7 Genotypes to Colorectal Cancer Susceptibility in Taiwan
}

\author{
TE-CHENG YUEH ${ }^{1,2,3,4}$, CHENG-NAN WU ${ }^{5 *}$, YI-WEN HUNG ${ }^{6 *}$, WEN-SHIN CHANG ${ }^{3}$, \\ CHUN-KAI FU ${ }^{1,2}$, JEN-SHENG PEI ${ }^{7}$, MING-HSIEN WU ${ }^{1,2}$, YI-LIANG LAI ${ }^{2}$, YI-MIN LEE ${ }^{5}$, \\ SHIOU-TING YEN ${ }^{3}$, HSIN-TING LI ${ }^{3}$, CHIA-WEN TSAI ${ }^{3,5}$ and DA-TIAN BAU ${ }^{1,3,8}$ \\ ${ }^{I}$ Graduate Institute of Biomedical Sciences, China Medical University, Taichung, Taiwan, R.O.C.; \\ ${ }^{2}$ Taichung Armed Forces General Hospital, Taichung, Taiwan, R.O.C.; \\ ${ }^{3}$ Terry Fox Cancer Research Laboratory, Translational Medical Research Center, \\ China Medical University Hospital, Taichung, Taiwan, R.O.C.; \\ ${ }^{4}$ National Defence Medical Center, Taipei, Taiwan, R.O.C.; \\ ${ }^{5}$ Department of Medical Laboratory Science and Biotechnology, \\ Central Taiwan University of Science and Technology, Taichung, Taiwan, R.O.C.; \\ ${ }^{6}$ Department of Medicine Research, Taichung Veterans General Hospital, Taichung, Taiwan, R.O.C.; \\ ${ }^{7}$ Department of Pediatrics, Taoyuan General Hospital, Ministry of Health and Welfare, Taoyuan, Taiwan, R.O.C.; \\ ${ }^{8}$ Department of Bioinformatics and Medical Engineering, Asia University, Taichung, Taiwan, R.O.C.
}

\begin{abstract}
Background/Aim: Matrix metalloproteinases (MMPs) play important roles in inflammation and carcinogenesis, but the genotypic role of MMP-7 has never been investigated in colorectal cancer (CRC) among the Taiwanese. Therefore, in this study we aimed to evaluate the contribution of MMP-7 genotypes to the risk of CRC in Taiwan. Materials and Methods: In this case-control study, MMP-7 A-181G and C-153T promoter genotypes were determined and their association with CRC risk were investigated among 362 CRC patients and 362 age-and gender-matched healthy controls. In addition, the interaction of MMP-7 genotypes and personal behaviors were also examined. Results: The percentages of variant $A G$ and $G G$ for MMP-7 A-181G genotypes were $10.5 \%$ and $1.7 \%$ in the CRC group and $11.9 \%$ and $2.2 \%$ in the control group, respectively ( $p$ for trend=0.7145). The allelic frequency distribution analysis showed that the variant $G$ allele of MMP-7 A-181G
\end{abstract}

This article is freely accessible online.

\footnotetext{
*These Authors contributed equally to this study.

Correspondence to: Da-Tian Bau and Chia-Wen Tsai, Terry Fox Cancer Research Laboratory, Translational Medical Research Center, China Medical University Hospital, 2 Yuh-Der Road, Taichung, 404 Taiwan, R.O.C. Tel: +886 422053366 (Ext. 5805), e-mail: datian@mail.cmuh.org.tw; artbau2@gmail.com
}

Key Words: Colorectal cancer, genotype, $M M P-7$, polymorphism, Taiwan. conferred a slight but non-significant decreased CRC susceptibility to the wild-type $C$ allele (odds ratio $(O R)=0.86$, $95 \%$ confidence interval $(C I)=0.64-1.31, p=0.37)$. Taiwanese all harbour the CC genotype at MMP-7 C-153T. As for the gene-lifestyle interaction, there were no obvious joint effects of MMP-7 A-181G genotype on the risk of CRC among ever smoker, alcohol drinker, non-smoker or non-drinker subgroups. No statistically significant correlation was observed between MMP-7 A-181G genotypic distributions and age, gender, tumor size, location or metastasis status. Conclusion: The genotypes of MMP-7 A-181G may play an indirect role in determining personal susceptibility to CRC and prognosis. The further genotyping work on MMP-7 and other genes (such as other MMPs, oncogenes and tumor suppression genes) on CRC susceptibility and prognosis, should be taken into consideration spontaneously in the precision medicine era.

Colorectal cancer (CRC) has been one of the leading causes of cancer associated with significant morbidity and mortality worldwide $(1,2)$. Globally, CRC is the third most common cancer among males and the second among females. Nevertheless, CRC incidence and mortality rates vary markedly across the globe with regional differences that can sometimes be 10 -fold $(1,2)$. In Taiwan, the incidence and mortality of CRC has occupied the first and third places among the common types of cancer for many years and its high incidence has been proposed to be closely associated with dietary changes to Western food style and a decreased consumption of dietary fiber or grain-made foods. From the epidemiological viewpoint, studies have attributed more than 
$85 \%$ of CRC etiology to risk environmental factors, particularly meat consumption, cigarette smoking, exposure to carcinogenic aromatic amines, such as arylamines and heterocyclic amines $(3,4)$. Statistically, $15-20 \%$ of CRC cases are with strong familial cancer history that have interested the molecular epidemiologists to figure out additional genomic susceptibility factors (5-7). In Taiwan, although specific biomarkers for CRC prediction and detection have keeping on being reported in the decade (8-12), the interactions among the genomic and environmental risk factors, such as smoking and alcohol drinking are mostly unknown.

In our body, MMP-7 has been found to be constitutively produced from the epithelial cells of mammary and parotid glands, pancreas, liver, prostate and peribronchial glands of the lung (13). From the results of the promoter assay in 2001, the basal promoter activity was higher in promoter constructs harboring the combination of the two rare alleles of $M M P-7$ at A-181G (rs11568818) and C-153T (rs11568819) (14), and these genotypic polymorphisms were associated with altered risk of coronary artery dimensions (14). In cancer genomic association studies, the genotypic polymorphisms of $M M P-7$ were investigated of their association with many types of cancer, including oral, lung, breast, esophageal, gastric, gallbladder, bladder, cervical cancer, astrocytoma, childhood leukemia and renal cell carcinoma (15-27), and colorectal cancer $(28,29)$.

Horvat and colleagues found that higher frequency of GG genotype at MMP-7 A-181G (rs11568818) was found among the CRC patients with T3/T4 stage, N1/N2 stage and with lymphovascular invasion (29). Although the genotype and allele frequencies of $M M P-7$ A-181G did not differ between control and colorectal cancer groups or any clinicopathological parameters, the combined MMP7-181A-MMP11,607dupG-MMP3-1,171A-MMP12-82A haplotypes were significantly more frequent in CRC patients than in healthy controls (28). It seems that there may be differential effects of MMP-7 genotypes on CRC susceptibility among different ethics, and more investigations are needed to figure out the contribution of MMP-7 genotypes to CRC risk. In light of the above, we conducted a hospital-based case-control study to investigate the genotypes of $M M P-7$ firstly among Taiwanese and examine the association of $M M P-7$ genotypes with the risk of CRC in a representative Taiwanese population.

\section{Materials and Methods}

Investigated population. The target population included 724 subjects (362 CRC patients and 362 controls). Patients diagnosed with CRC were recruited at the outpatient clinics of general surgery during the period of 2002 and 2008 at the China Medical University Hospital by the excellent surgery teams under the supervision of Jeng L.B. and Yang M.D. The clinical characteristics of patients, including histological details, were all graded and defined by expert surgeons (8-11). All participants have completed a self-administered questionnaire and provided a 5-ml sample of peripheral blood for genotyping work. An equal number of non-cancer healthy volunteers were selected as controls by matching for age, gender and some indulgences after initial random sampling from the Health Examination Cohort of the Hospital with the help of colleagues in the Department of Family Medicine. The exclusion criteria of the control group included previous malignancy, metastasized cancer from other or unknown origin and any familial or genetic diseases. This study was approved by the Institutional Review Board of the China Medical University Hospital (IRB project identification coding number: DMR99-IRB-108) and written informed consents were obtained from all the participants with the help of Tissue Bank of China Medical University Hospital. The selective demographic information for the participants is summarized in Table I.

Genotyping conditions. Genomic DNA was extracted from peripheral blood leukocytes with a QIAamp Blood Mini Kit (Blossom, Taipei, Taiwan), stored long-term at $-80^{\circ} \mathrm{C}$, diluted and aliquoted for genotyping as a working stock at $-20^{\circ} \mathrm{C}$ as we frequently conducted (30-32). The $M M P-7$ genotyping methodology including the designing of the specific primers and the selection of restriction enzymes, were exactly the same as our currently published papers $(17,25,27)$. Concisely, the polymerase chain reaction (PCR) cycling conditions were: one cycle at $94^{\circ} \mathrm{C}$ for $5 \mathrm{~min} ; 35$ cycles of $94^{\circ} \mathrm{C}$ for $30 \mathrm{~s}, 59^{\circ} \mathrm{C}$ for $30 \mathrm{~s}$ and $72^{\circ} \mathrm{C}$ for $30 \mathrm{~s}$, and a final extension at $72^{\circ} \mathrm{C}$ for $10 \mathrm{~min}$. The genotyping PCR for MMP-7 A-181G was conducted using the forward 5'-TGGTACCA TAATGTCCTGAATG-3' and the reverse 5'-TCGTTATTGGCA GGAAGCACACAATGAATT-3' primer pairs. The obtained $150 \mathrm{bp}$ PCR products were then digested with EcoRI and resulted in two fragments of 120 and $30 \mathrm{bp}$ when the $\mathrm{G}$ allele was present. In the presence of the A allele, the $150 \mathrm{bp}$ fragment remained intact. As for the MMP-7 C-153T, direct sequencing PCR was conducted with the same primers as for $M M P-7$ A-181G. After amplification, the PCR products were subject to digestion and separation using $3 \%$ agarose gel electrophoresis. All the genotypic processing was repeated by two expert researchers independently and blindly, and their results were $100 \%$ concordant to each other. In addition, the success rate of PCR-restrictive fragment length polymorphism (RFLP) is $100 \%$, and the genotypes of $5 \%$ of the participants in both the control and CRC patient groups were analyzed by PCR direct sequencing (Genomics BioSci \& Tech Co). The concordance between direct sequencing and PCR-RFLP methods was $100 \%$.

Statistical analyses. The Student's $t$-test was applied for the comparison of ages between the CRC cases and the control groups. Pearson's Chi-square or Fisher's exact test (when any cell analyzed was less than 5, such as those in Tables IV-VI) was applied to compare the distribution of the MMP-7 genotypes among the subgroups. The associations between MMP-7 genotypes and CRC risk were estimated by computing odds ratios (ORs) and their $95 \%$ confidence intervals (CIs) from logistic regression analysis. Statistically, any difference at $p<0.05$ was taken as significant between the two groups compared.

\section{Results}

The frequency distributions of selected demographic characters, including age and gender for the 362 CRC patients in the case group and 362 non-cancer healthy subjects in the control group, are summarized and compared 
Table I. Summary of selected data from 362 patients with colorectal cancer and 362 matched non-cancer healthy controls.

\begin{tabular}{|c|c|c|c|c|c|}
\hline \multirow[t]{2}{*}{ Characteristic } & \multicolumn{2}{|c|}{$\begin{array}{l}\text { Controls } \\
(\mathrm{n}=362)\end{array}$} & \multicolumn{2}{|c|}{$\begin{array}{c}\text { Cases } \\
(\mathrm{n}=362)\end{array}$} & \multirow[t]{2}{*}{$p$-Value ${ }^{a}$} \\
\hline & $\mathrm{n}$ & $\%$ & $\mathrm{n}$ & $\%$ & \\
\hline \multicolumn{6}{|l|}{ Age (years) } \\
\hline$\leq 60$ & 93 & $25.7 \%$ & 95 & $26.2 \%$ & 0.8654 \\
\hline$>60$ & 269 & $74.3 \%$ & 267 & $73.8 \%$ & \\
\hline \multicolumn{6}{|l|}{ Gender } \\
\hline Male & 209 & $57.7 \%$ & 203 & $56.1 \%$ & 0.6525 \\
\hline Female & 153 & $42.3 \%$ & 159 & $43.9 \%$ & \\
\hline \multicolumn{6}{|c|}{ Tumor size $(\mathrm{cm})$} \\
\hline$<5$ & & & 195 & $53.9 \%$ & \\
\hline$\geq 5$ & & & 167 & $46.1 \%$ & \\
\hline \multicolumn{6}{|l|}{ Location } \\
\hline Colon & & & 257 & $71.0 \%$ & \\
\hline Rectum & & & 105 & $29.0 \%$ & \\
\hline \multicolumn{6}{|c|}{ Lymph node metastasis } \\
\hline Negative & & & 210 & $58.0 \%$ & \\
\hline Positive & & & 152 & $42.0 \%$ & \\
\hline
\end{tabular}

SD, aStandard deviation; abased on Chi-square test without Yates' correction.

in Table I. In addition, tumor size, location, and lymph node metastasis status are also summarized and compared in Table I. Since we applied frequency matching to recruit non-cancer healthy subjects as controls, the results showed that there was no difference in respects of the distributions of age and gender between the control and case groups $(p=0.8654$ and 0.6525 , respectively) (Table I). The patients with tumor size $<5 \mathrm{~cm}$ and $\geq 5 \mathrm{~cm}$ were 195 and 167 , respectively. The patients with tumor location at colon and rectum were 257 and 105 , respectively. The patients with and without lymph node metastasis were 152 and 210, respectively (Table I).

The distributions of the MMP-7 A-181G and C-153T genotypes among the 362 non-cancer healthy controls and the 362 CRC patients are presented and analyzed in Table II. First, the results showed that the genotype of MMP-7 C153T were the same among all the Taiwanese (Table II lower panel). Second, the genotypes of $M M P-7 \mathrm{~A}-181 \mathrm{G}$ were not differently distributed between case and control groups ( $\mathrm{p}$ for trend=0.7145) (Table II upper panel). In detail, the MMP-7 A-181G homozygous GG and heterozygous AG were not associated with altered CRC risk, compared with wild-type CC genotype (adjusted $\mathrm{OR}=0.74$ and $0.88,95 \% \mathrm{CI}=0.35-2.34$ and $0.61-1.23, p=0.5688$ and 0.5371 , respectively; Table II upper panel). In the dominant model, there was no association between the $\mathrm{AG}+\mathrm{GG}$ genotype of $M M P-7 \mathrm{~A}-$ $181 \mathrm{G}$ and CRC risk, compared with AA wild-type genotype (adjusted $\mathrm{OR}=0.83,95 \% \mathrm{CI}=0.58-1.57, p=0.4410$, Table II upper panel).
Table II. Distributions of matrix metalloproteinas-7 A-181G and C-153T genotypic frequencies among colorectal cancer patients and healthy controls.

\begin{tabular}{lcccc}
\hline & $\begin{array}{c}\text { Cases, } \\
\mathrm{n}(\%)\end{array}$ & $\begin{array}{c}\text { Controls, } \\
\mathrm{n}(\%)\end{array}$ & $\begin{array}{c}\text { Adjusted OR } \\
(95 \% \mathrm{CI})^{\mathrm{a}}\end{array}$ & $p$-Value \\
\hline A-181G & & & & \\
AA & $318(87.8)$ & $311(85.9)$ & 1.00 (Reference) & \\
AG & $38(10.5)$ & $43(11.9)$ & $0.88(0.61-1.23)$ & 0.5371 \\
GG & $6(1.7)$ & $8(2.2)$ & $0.74(0.35-2.34)$ & 0.5688 \\
AG+GG & $44(12.2)$ & $51(14.1)$ & $0.83(0.58-1.57)$ & 0.4410 \\
$p_{\text {trend }}$ & & & & 0.7145 \\
-153T & & & - & \\
CC & $362(100.0)$ & $362(100.0)$ & 1.00 (Reference) & \\
CT & $0(0.0)$ & $0(0.0)$ & -- & \\
TT & $0(0.0)$ & $0(0.0)$ & - & \\
$p_{\text {trend }}$ & & & & \\
\hline
\end{tabular}

OR, Odds ratio; CI, confidence interval. aData have been adjusted for confounding factors age, gender, smoking, alcohol and betel quid consumption. bBased on Chi-square test without Yates' correction.

Table III. Allelic frequencies for matrix metalloproteinas-7 A-181G and C-153T polymorphisms among the colorectal cancer patients and healthy controls.

\begin{tabular}{|c|c|c|c|c|}
\hline Allelic type & $\begin{array}{l}\text { Cases, } \\
\mathrm{n}(\%) \\
\mathrm{n}=724\end{array}$ & $\begin{array}{c}\text { Controls, } \\
\mathrm{n}(\%) \\
\mathrm{n}=724\end{array}$ & $\begin{array}{c}\text { Adjusted OR } \\
(95 \% \mathrm{CI})^{\mathrm{a}}\end{array}$ & $p$-Value ${ }^{\mathrm{b}}$ \\
\hline \multicolumn{5}{|l|}{ A-181G } \\
\hline Allele A & $674(93.1)$ & 665 (91.9) & 1.00 (Reference) & 0.3700 \\
\hline Allele G & $50(6.9)$ & $59(8.1)$ & $0.86(0.64-1.31)$ & \\
\hline \multicolumn{5}{|l|}{ C-153T } \\
\hline Allele C & $724(100.0)$ & $724(100.0)$ & 1.00 (Reference) & \\
\hline Allele $\mathrm{T}$ & $0(0.0)$ & $0(0.0)$ & -- & \\
\hline
\end{tabular}

OR, Odds ratio; CI, confidence interval. aData have been adjusted for confounding factors age, gender, smoking, alcohol and betel quid consumption. bBased on Chi-square test without Yates' correction.

To confirm the results in Table II, analysis of allelic frequency distribution for the MMP-7 A-181G and C-153T was further conducted and the results are presented in Table III. Supporting the findings that genotype of MMP-7 A-181G was not associated with CRC risk, the variant allele $\mathrm{G}$ was found at $6.9 \%$ in the case group, nonsignificantly of similar level with that of $8.1 \%$ in the control group (adjusted $\mathrm{OR}=0.86,95 \% \mathrm{CI}=0.64-1.31$, $p=0.3700$ ) (Table III upper panel). At the same time, there was no $\mathrm{T}$ allele found in any of the subject investigated (Table III lower panel).

Since smoking and alcohol drinking habits are well-known risk factors for CRC in Taiwan, we were interested in 
Table IV. Odds ratios for matrix metalloproteinas-7 A-181G genotype and colorectal cancer after stratification by smoking status.

\begin{tabular}{|c|c|c|c|c|c|c|c|c|c|c|}
\hline \multirow[t]{2}{*}{ Genotype } & \multicolumn{2}{|c|}{ Non-smokers, $\mathrm{n}$} & \multirow[t]{2}{*}{$\mathrm{OR}(95 \% \mathrm{CI})^{\mathrm{b}}$} & \multirow[t]{2}{*}{$\mathrm{aOR}(95 \% \mathrm{CI})^{\mathrm{a}}$} & \multirow[t]{2}{*}{$p$-Value } & \multicolumn{2}{|c|}{ Smokers, $\mathrm{n}$} & \multirow[t]{2}{*}{ OR $(95 \% \mathrm{CI})^{\mathrm{a}}$} & \multirow[t]{2}{*}{$\mathrm{aOR}(95 \% \mathrm{CI})^{\mathrm{b}}$} & \multirow[t]{2}{*}{$p$-Value } \\
\hline & Controls & Cases & & & & Controls & Cases & & & \\
\hline AA & 240 & 238 & 1.00 (ref) & 1.00 (ref) & & 71 & 80 & 1.00 (ref) & 1.00 (ref) & \\
\hline $\mathrm{AG}$ & 34 & 28 & $0.83(0.49-1.41)$ & $0.87(0.54-1.73)$ & 0.4927 & 9 & 10 & $0.99(0.38-2.56)$ & $1.04(0.57-2.18)$ & 0.9771 \\
\hline GG & 4 & 5 & $1.26(0.33-4.75)$ & $1.14(0.45-2.58)$ & 0.7513 & 4 & 1 & $0.22(0.02-2.03)$ & $0.48(0.53-1.89)$ & 0.1958 \\
\hline Total & 278 & 271 & & & & 84 & 91 & & & \\
\hline
\end{tabular}

$\mathrm{CI}$, Confidence interval; a ${ }^{\mathrm{OR}}$, adjusted odds ratio. ${ }^{\mathrm{a} B y}$ multivariate logistic regression analysis; b by multivariate logistic regression analysis after adjusted of age, gender and alcohol drinking status; *statistically significant.

Table V. Odds ratios for matrix metalloproteinas-7 A-181G genotype and colorectal cancer after stratification by alcohol drinking status.

\begin{tabular}{|c|c|c|c|c|c|c|c|c|c|c|}
\hline \multirow[t]{2}{*}{ Genotype } & \multicolumn{2}{|c|}{ Non-drinker, n } & \multirow[t]{2}{*}{ OR $(95 \% \mathrm{CI})^{\mathrm{a}}$} & \multirow[t]{2}{*}{$\mathrm{aOR}(95 \% \mathrm{CI})^{\mathrm{b}}$} & \multirow[t]{2}{*}{$p$-Value } & \multicolumn{2}{|c|}{ Drinkers, $\mathrm{n}$} & \multirow[t]{2}{*}{ OR $(95 \% \mathrm{CI})^{\mathrm{a}}$} & \multirow[t]{2}{*}{$\mathrm{aOR}(95 \% \mathrm{CI})^{\mathrm{b}}$} & \multirow[t]{2}{*}{$p$-Value } \\
\hline & Controls & Cases & & & & Controls & Cases & & & \\
\hline AA & 268 & 283 & 1.00 (ref) & 1.00 (ref) & & 43 & 35 & 1.00 (ref) & 1.00 (ref) & \\
\hline AG & 36 & 30 & $0.79(0.47-1.32)$ & $0.85(0.71-1.29)$ & 0.3644 & 7 & 8 & $1.40(0.46-4.25)$ & $1.24(0.47-3.21)$ & 0.5472 \\
\hline GG & 7 & 5 & $0.68(0.21-2.16)$ & $0.79(0.54-1.93)$ & 0.5063 & 1 & 1 & $1.23(0.07-20.36)$ & $1.12(0.38-17.87)$ & 1.0000 \\
\hline Total & 311 & 318 & & & & 51 & 44 & & & \\
\hline
\end{tabular}

$\mathrm{CI}$, Confidence interval; a $\mathrm{OR}$, adjusted odds ratio. ${ }^{\mathrm{B} B y}$ multivariate logistic regression analysis; b by multivariate logistic regression analysis after adjusted of age, gender and smoking status; *statistically significant.

investigating the interactions between the genotype of $M M P$ 7 A-181G and personal cigarette smoking and alcohol drinking behaviors. Firstly, among smokers, those with AG and GG genotypes at MMP-7 A-181G were at 0.83 - and 1.26-fold odds of having CRC (95\% CI=0.49-1.41 and 0.33 $4.75, p=0.4927$ and 0.7513 , respectively) conferring no risky effect, while this non-significant effect was also the case for non-smokers (Table IV). After adjusting for age, gender and alcohol drinking status, statistical non-significance still existed at a similar level (Table IV). Secondly, among alcohol drinkers, those with AG and GG genotypes at $M M P$ 7 A-181G were at 0.79 - and 0.68 -fold odds of having CRC (95\% $\mathrm{CI}=0.47-1.32$ and 0.21-2.16, $p=0.3644$ and 0.5063 , respectively) conferring no risky effect, while this nonsignificant effect was also the case for non-drinkers (Table V). After adjusting for age, gender and smoking status, results were still non-significant either (Table V).

The correlations between genotypes of $M M P-7$ A-181G and clinicopathological features of $362 \mathrm{CRC}$ patients were further stratified and analyzed in Table VI. No statistically significant correlation was observed between MMP-7 A-181G genotypic distributions and age, gender, tumor size, location or metastasis status (all $p>0.05$ ) (Table VI).
Table VI. Correlation between matrix metalloproteinas-7 A-181G genotypes and clinicopathological properties of 362 colorectal cancer patients.

\begin{tabular}{|c|c|c|c|c|c|}
\hline \multirow[t]{2}{*}{ Characteristics } & \multirow{2}{*}{$\begin{array}{l}\text { Case } \\
\text { number }\end{array}$} & \multicolumn{3}{|c|}{ Genotypes } & \multirow[t]{2}{*}{$p$-Value } \\
\hline & & $\mathrm{AA}(\%)$ & $\mathrm{AG}(\%)$ & GG $(\%)$ & \\
\hline \multicolumn{6}{|l|}{ Age (years) } \\
\hline$\leq 60$ & 95 & $85(89.5)$ & $8(8.4)$ & $2(2.1)$ & \\
\hline$>60$ & 267 & $233(87.3)$ & $30(11.2)$ & $4(1.5)$ & 0.6964 \\
\hline \multicolumn{6}{|l|}{ Gender } \\
\hline Male & 203 & $180(88.7)$ & $19(9.4)$ & $4(1.9)$ & \\
\hline Female & 159 & $138(86.8)$ & 19 (11.9) & $2(1.3)$ & 0.6444 \\
\hline \multicolumn{6}{|l|}{ Tumor size } \\
\hline$<5 \mathrm{~cm}$ & 195 & $166(85.1)$ & $24(12.3)$ & $5(2.6)$ & \\
\hline$\geq 5 \mathrm{~cm}$ & 167 & $152(91.0)$ & $14(8.4)$ & $1(0.6)$ & 0.1517 \\
\hline \multicolumn{6}{|l|}{ Location } \\
\hline Colon & 257 & $220(85.6)$ & $32(12.5)$ & $5(1.9)$ & \\
\hline Rectum & 105 & $98(93.3)$ & $6(5.7)$ & $1(1.0)$ & 0.1241 \\
\hline \multicolumn{6}{|l|}{$\begin{array}{l}\text { Lymph node } \\
\text { metastasis }\end{array}$} \\
\hline Negative & 210 & $188(89.5)$ & $18(8.6)$ & $4(1.9)$ & \\
\hline Positive & 152 & $130(85.5)$ & $20(13.2)$ & $2(1.3)$ & 0.3479 \\
\hline
\end{tabular}

aBased on Chi-square test without Yates's correction; *statistically significant. 


\section{Discussion}

Under normal conditions, MMP-7 is in charge of degrading several ECM macromolecules such as casein, type I-V gelatins, fibronectins and proteoglycans (33). There are a few investigations specifically examine the phenotypic role of MMP-7 in CRC carcinogenesis. Firstly, the MMP-7 protein is found to be highly expressed in the luminal surface of dysplastic glands in human CRC patients (33). Secondly, from the clinical practice viewpoint, MMP-7 inhibitors can potentially be applied to control the invasive capacity of cancers (34). Thirdly, MMP7 was found to be highly expressed in advanced colorectal adenomatous and involved in converting colorectal adenomas into malignant state and facilitating the cancer growth (35). According to the highlights above, it is reasonable that hereditary genomic information coded by various polymorphisms on $M M P-7$ may determine differential responses and personal susceptibility to $\mathrm{CRC}$ in the processes in inflammation, tumor initiation, invasion and metastasis.

In the current study, we firstly examined the contribution of MMP-7 genotypes to CRC susceptibility in Taiwan, where $\mathrm{CRC}$ is the highest prevalent cancer in the country for many years. The polymorphisms at the promoter region of the genes are most likely to determine the expression level of it. Thus, in the research design for selection the polymorphic sites, we aimed at investigating the most common examined promoter polymorphism at MMP-7 A-181G. In addition, we have also investigated the genotypes at $M M P-7 \mathrm{C}-153 \mathrm{~T}$, which is also a polymorphic site at promoter region while less examined by genomic scientists. The results showed that the $\mathrm{G}$ allele of MMP7 A-181G were non-significantly associated with altered risk to CRC (Tables II and III). There were no variant genotypes at MMP-7 C-153T for Taiwanese (Tables II and III). As far as we are aware, the current study is the first to reveal the genotypic contribution of $M M P-7$ promoter genotypes to CRC in Taiwan. Different from the previous findings that higher frequency of GG genotype at $M M P-7 \mathrm{~A}-$ $181 \mathrm{G}$ among the CRC patients with T3/T4 stage, N1/N2 stage and with lymphovascular invasion (29), we did not find similar correlation between the MMP-7 A-181G genotype and age, gender, tumor size, location or metastasis status (Table VI). This may be due to different target populations investigated, and the small percentages and numbers of those with GG genotypes at MMP-7 A-181G among Taiwanese.

The current findings may encourage genomic scientists to figure out the combinative effects among several genes on CRC and other diseases. Also, the contribution of MMP-7 protein to the ECM alteration during carcinogenesis in complex and should be taken into consideration with other MMPs. Our findings in cancer or clinicopathological parameter association and those of Woo are negative while analyzing only $M M P-7 \mathrm{~A}-181 \mathrm{G}$ itself, while the combined MMP7-181A-MMP1-1,607dupG-MMP3-1,171A-MMP12-
82A haplotypes were significantly more frequent in CRC patients than in healthy controls (28).

In conclusion, this study investigated the contribution of $M M P-7$ promoter genotypes and the interaction of them with smoking and alcohol drinking status to determine personal susceptibility to CRC. The genotypes of MMP-7 A-181G and C-153T may play an indirect role in determining personal susceptibility to $\mathrm{CRC}$ and the prognosis, the combinative effects of $M M P-7$ and other genes (such as other MMPs) on CRC susceptibility and prognosis, should be taken into consideration spontaneously in the precision medicine era.

\section{Conflicts of Interest}

The Authors declare no conflicts of interest in regard to this study.

\section{Acknowledgements}

We appreciate the Tissue-bank of China Medical University Hospital for their excellent technical assistance and all the subjects, doctors, nurses and colleagues. This study was supported mainly by the Taichung Armed Forces General Hospital (106A14) to Dr. Yueh, partially by Taichung Armed Forces General Hospital (106A05) to Dr. Fu, Taichung Veterans General Hospital (TCVGH-CTUST1077701) to Dr. Hung and Dr. Wu, and partially by research grant from Taiwan Ministry of Health and Welfare Clinical Trial and Research Center of Excellence (MOHW107-TDU-B-212-123004).

\section{References}

1 Douaiher J, Ravipati A, Grams B, Chowdhury S, Alatise O and Are C: Colorectal cancer-global burden, trends, and geographical variations. J Surg Oncol 115: 619-630, 2017.

2 Arnold M, Sierra MS, Laversanne M, Soerjomataram I, Jemal A and Bray F: Global patterns and trends in colorectal cancer incidence and mortality. Gut 66: 683-691, 2017.

3 Nagini S: Carcinoma of the stomach: A review of epidemiology, pathogenesis, molecular genetics and chemoprevention. World J Gastrointest Oncol 4: 156-169, 2012.

4 Jayasurya R, Sathyan KM, Lakshminarayanan K, Abraham T, Nalinakumari KR, Abraham EK, Nair MK and Kannan S: Phenotypic alterations in $\mathrm{Rb}$ pathway have more prognostic influence than p53 pathway proteins in oral carcinoma. Mod Pathol 18: 1056-1066, 2005.

5 Butterworth AS, Higgins JP and Pharoah P: Relative and absolute risk of colorectal cancer for individuals with a family history: a meta-analysis. Eur J Cancer 42: 216-227, 2006.

6 Houlston RS and Tomlinson IP: Polymorphisms and colorectal tumor risk. Gastroenterology 121: 282-301, 2001.

7 Rasool S, Rasool V, Naqvi T, Ganai BA and Shah BA: Genetic unraveling of colorectal cancer. Tumour Biol 35: 5067-5082, 2014.

8 Yueh TC, Chou AK, Gong CL, Fu CK, Pei JS, Wu MH, Tsai CW, Chang WS, Hsiao CL, Yen ST, Li HT and Bau DT: The contribution of excision repair cross-complementing group 1 genotypes to colorectal cancer susceptibility in Taiwan. Anticancer Res 37: 2307-2313, 2017. 
9 Huang CY, Tsai CW, Hsu CM, Chang WS, Shui HA and Bau DT: The significant association of CCND1 genotypes with colorectal cancer in Taiwan. Tumour Biol 36: 6533-6540, 2015.

10 Yang MD, Tsai CW, Chang WS, Tsou YA, Wu CN and Bau DT: Predictive role of XRCC5/XRCC6 genotypes in digestive system cancers. World J Gastrointest Oncol 3: 175-181, 2011.

11 Yang MD, Tsai RY, Liu CS, Chang CH, Wang HC, Tsou YA, Wang CH, Lin CC, Shyue SK and Bau DT: Association of Caveolin-1 polymorphisms with colorectal cancer susceptibility in Taiwan. World J Gastrointest Oncol 2: 326-331, 2010.

12 Shi MD, Chen JH, Sung HT, Lee JS, Tsai LY and Lin HH: CXCL12-G801A polymorphism modulates risk of colorectal cancer in Taiwan. Arch Med Sci 9: 999-1005, 2013.

13 Saarialho-Kere UK, Crouch EC and Parks WC: Matrix metalloproteinase matrilysin is constitutively expressed in adult human exocrine epithelium. J Invest Dermatol 105: 190-196, 1995.

14 Jormsjo S, Whatling C, Walter DH, Zeiher AM, Hamsten A and Eriksson P: Allele-specific regulation of matrix metalloproteinase-7 promoter activity is associated with coronary artery luminal dimensions among hypercholesterolemic patients. Arterioscler Thromb Vasc Biol 21: 1834-1839, 2001

15 Lu Z, Wang Y, Zhang Q, Zhang X, Wang S, Xie H, Li Y, Jiao B and Zhang J: Association between the functional polymorphism in the matrix metalloproteinase-7 promoter and susceptibility to adult astrocytoma. Brain Res 1118: 6-12, 2006.

16 Zhang J, Jin X, Fang S, Wang R, Li Y, Wang N, Guo W, Wang Y, Wen D, Wei L, Dong Z and Kuang G: The functional polymorphism in the matrix metalloproteinase-7 promoter increases susceptibility to esophageal squamous cell carcinoma, gastric cardiac adenocarcinoma and non-small cell lung carcinoma. Carcinogenesis 26: 1748-1753, 2005.

17 Chou AK, Hsiao CL, Shih TC, Wang HC, Tsai CW, Chang WS, Liu LC, Way TD, Chung JG and Bau DT: The contribution of matrix metalloproteinase-7 promoter genotypes in breast cancer in Taiwan. Anticancer Res 37: 4973-4977, 2017.

18 Malik MA, Sharma KL, Zargar SA and Mittal B: Association of matrix metalloproteinase-7 $(-181 \mathrm{~A}>\mathrm{G})$ polymorphism with risk of esophageal squamous cell carcinoma in Kashmir Valley. Saudi J Gastroenterol 17: 301-306, 2011.

19 Fang WL, Liang WB, Gao LB, Zhou B, Xiao FL and Zhang L: Genetic polymorphisms in Matrix Metalloproteinases -1 and -7 and susceptibility to gastric cancer: an association study and metaanalysis. Iran J Allergy Asthma Immunol 12: 203-210, 2013.

20 Moreno-Ortiz JM, Gutierrez-Angulo M, Partida-Perez M, Peregrina-Sandoval J, Ramirez-Ramirez R, Muniz-Mendoza R, Suarez-Villanueva S, Centeno-Flores M, Maciel-Gutierrez V, Cabrales-Vazquez JE and Ayala-Madrigal ML: Association of MMP7-181A/G and MMP13-77A/G polymorphisms with colorectal cancer in a Mexican population. Genet Mol Res 13: 3537-3544, 2014

21 Sharma KL, Misra S, Kumar A and Mittal B: Higher risk of matrix metalloproteinase (MMP-2, 7, 9) and tissue inhibitor of metalloproteinase (TIMP-2) genetic variants to gallbladder cancer. Liver Int 32: 1278-1286, 2012.

22 Wieczorek E, Reszka E, Wasowicz W, Grzegorczyk A, Konecki T, Sosnowski M and Jablonowski Z: MMP7 and MMP8 genetic polymorphisms in bladder cancer patients. Cent European J Urol 66: 405-410, 2014.

23 Xie B, Zhang Z, Wang H, Chen Z, Wang Y, Liang H, Yang G, Yang $\mathrm{X}$ and Zhang H: Genetic polymorphisms in MMP 2, 3, 7 , and 9 genes and the susceptibility and clinical outcome of cervical cancer in a Chinese Han population. Tumour Biol 37: 4883-4888, 2016.

24 Lievre A, Milet J, Carayol J, Le Corre D, Milan C, Pariente A, Nalet B, Lafon J, Faivre J, Bonithon-Kopp C, Olschwang S, Bonaiti-Pellie C, Laurent-Puig $\mathrm{P}$ and members of the $\mathrm{Ag}$ : Genetic polymorphisms of MMP1, MMP3 and MMP7 gene promoter and risk of colorectal adenoma. BMC Cancer 6: 270, 2006.

25 Liao CH, Chang WS, Hu PS, Wu HC, Hsu SW, Liu YF, Liu SP, Hung HS, Bau DT and Tsai CW: The contribution of MMP-7 promoter polymorphisms in renal cell carcinoma. In Vivo 31: 631-635, 2017.

26 Vairaktaris E, Serefoglou Z, Yapijakis C, Vylliotis A, Nkenke E, Derka S, Vassiliou S, Avgoustidis D, Neukam FW and Patsouris E: High gene expression of matrix metalloproteinase-7 is associated with early stages of oral cancer. Anticancer Res 27: 2493-2498, 2007.

27 Pei JS, Chou AK, Hsu PC, Tsai CW, Chang WS, Wu MF, Wu MH, Hsia TC, Cheng SP and Bau DT: Contribution of matrix metalloproteinase-7 genotypes to the risk of non-solid tumor, childhood leukemia. Anticancer Res 37: 6679-6684, 2017.

28 Woo M, Park K, Nam J and Kim JC: Clinical implications of matrix metalloproteinase- $1,-3,-7,-9,-12$, and plasminogen activator inhibitor-1 gene polymorphisms in colorectal cancer. J Gastroenterol Hepatol 22: 1064-1070, 2007.

29 Horvat M, Potocnik U, Repnik K, Kavalar R, Zadnik V, Potrc S and Stabuc B: Single nucleotide polymorphisms in Genes MACC1, RAD18, MMP7 and SDF-1a as prognostic factors in resectable colorectal cancer. Radiol Oncol 51: 151-159, 2017.

30 Pei JS, Chang WS, Hsu PC, Hung YW, Cheng SP, Tsai CW, Bau DT and Gong CL: The contribution of MMP-8 promoter genotypes to childhood leukemia. In Vivo 31: 1059-1064, 2017.

$31 \mathrm{Hu}$ PS, Chang WS, Chou AK, Hsia NY, Hung YW, Lin CW, Wu CW, Huang CY, Wu MF, Liao CH, Tsai CW, Bau DT and Gong CL: The association of MMP-8 genotypes with Pterygium. In Vivo 32: 41-46, 2018.

32 Shen TC, Chang WS, Tsai CW, Chao CY, Lin YT, Hsiao CL, Hsu CL, Chen WC, Hsia TC and Bau DT: The contribution of matrix metalloproteinase-1 promoter genotypes in Taiwan lung cancer risk. Anticancer Res 38: 253-257, 2018.

33 Yokoyama Y, Grunebach F, Schmidt SM, Heine A, Hantschel M, Stevanovic S, Rammensee HG and Brossart P: Matrilysin (MMP-7) is a novel broadly expressed tumor antigen recognized by antigen-specific T cells. Clin Cancer Res 14: 5503-5511, 2008.

34 Edman K, Furber M, Hemsley P, Johansson C, Pairaudeau G, Petersen J, Stocks M, Tervo A, Ward A, Wells E and Wissler L: The discovery of MMP7 inhibitors exploiting a novel selectivity trigger. ChemMedChem 6: 769-773, 2011.

35 Qasim BJ, Ali HH and Hussein AG: Immunohistochemical expression of matrix metalloproteinase-7 in human colorectal adenomas using specified automated cellular image analysis system: a clinicopathological study. Saudi J Gastroenterol 19: 23-27, 2013.

Received February 14, 2018 Revised March 22, 2018 Accepted March 23, 2018 